\title{
DIMENSIONES SUBJETIVAS DEL CAMBIO SOCIAL
}

\author{
José R. Torregrosa Peris
}

Desde los orígenes mismos de la ciencia moderna ha habido una tendencia hacia la práctica y por tanto hacia la técnica. La búsqueda en aplicaciones y el dominio sobre la naturaleza han constituido siempre una dimensión del saber teórico. Pero esa tendencia hacia la interrelación del saber científico y técnico, entre investigación teórica y aplicada, parece sin embargo inherente a las condiciones de evolución de nuestras sociedades actuales.

Los sociólogos de la ciencia han puesto de manifiesto la cada vez mayor proximidad entre los avances científicos y sus posibles aplicaciones prácticas, entre los resultados de la investigación y su instrumentalización (técnico-económica). Ciencia y tecnología aparecen (y subrayo aparecen) cada vez más como un binomio indesligable. El proceso de racionalización, en el sentido de Weber, induce a esa conversión y asimilación de la ciencia en fuerza productiva. $Y$ así, los analistas de la llamada sociedad postindustrial consideran, en efecto, que el principio axial de su estructura es la centralidad y la codificación del conocimiento teórico.

De ahí que sus instituciones fundamentales sean aquéllas que se dedican a la producción de ese conocimiento teórico: universidades, academias, institutos de investigación, etc. La importancia de estas instituciones se deriva, claro está, de que la producción está basada directamente en la investigación científico-técnica. Todo esto ha facilitado una relación de cada vez mayor dominio del hombre sobre la naturaleza. Aparentemente, la vieja pretensión comtiana de «saber para prever y prever para poder», 
encuentra de este modo su expresión en la institucionalización de la ciencia.

El binomio ciencia-tecnología se ha convertido en un elemento primordial del proceso de modernización. La imagen de la ciencia como progresiva acumulación de saberes que permiten un mayor dominio y control de la naturaleza alimentaba la esperanza de una constante mejora en las condiciones generales de vida y de un perfeccionamiento de la propia condición humana. El progreso no sólo sería material, sino también moral; ambos conllevarían un mayor grado de felicidad y satisfacción generalizadas.

Pero esta idea no ha podido ocultar en ningún momento - ahí está una gran parte de la tradición sociológica para demostrarlo- que los procesos de transición a la modernidad han ido acompañados de una dislocación de las instituciones y los vínculos tradicionales, y de angustias y sufrimientos para muchos millones de seres humanos. El siglo veinte, con dos guerras mundiales y otras muchas parciales, con la utilización de la energía atómica para la destrucción de seres humanos, con genocidios planificados, etcétera, no permite pensar que este proceso de modernización tenga menos consecuencias negativas para la especie humana.

No trato de apoyar, con esta elemental constatación, una posición antiprogresista, o de minimizar los fantásticos logros que la ciencia y la técnica suponen. Trato, por el contrario, de subrayar un hecho, por otra parte obvio: el de que las consecuencias de la transición a la modernidad no se ajustan a lo que la ideología del progreso prometía; y que si el desarrollo científico-técnico ha conducido a la resolución de muchos graves problemas, no por ello ha dejado de plantear y de provocar otros igualmente graves.

Lo que esta observación genérica nos permite también ver es que no cabe pensar en términos excesivamente simples y unidireccionales respecto al cambio tecnológico. No existe una lógica intrínseca unidireccional respecto al impacto que la introducción de nuevas tecnologías pueda tener en el sistema social, en las relaciones de las partes que lo integran y en las personas concretas. No cabe deducir la inexorabilidad de un determinismo tecnológico, más o menos explícitamente formulado o dejado entrever, como señuelo de un progreso social necesario al que acríticamente debamos apuntarnos. Si bien la ciencia y la técnica tienen una estructura intrínseca que, una vez dèsarrollada, ejerce un conjunto de constricciones genéricas que pueden considerarse de validez universal, su impacto social, sus consecuencias o efectos específicos dependerán totalmente del contexto de relaciones sociales en el que se inscriban. La tecnología, por tanto, en sus posibles efectos, es necesario considerarla en relación con los otros elementos que integran el sistema socio-cultural.

El sentido último de sus consecuencias dependerá de los valores, manifiestos o latentes, que orientan la acción de sistema que la genera, la difun- 
de o la utiliza. Por supuesto que esos valores se revelan ya en el hecho de generarla, de difundirla o de utilizarla; ella misma es expresión objetivada de ciertos fines.

Estas consideraciones las hago con el ánimo de mostrar la pertinencïa de una cierta subjetivización en la perspectiva sobre el cambio social. Cuando hablo de dimensiones subjetivas no quiero decir sólo factores psicológicos, en un intento de complementar factores considerados sociológicos o estructurales. Quiero señalar el hecho de que los procesos sociales, de cambio o funcionales, no son simplemente procesos mecánicos a los que pasivamente se adaptan quienes en ellos participan o los sufren, sino entramados de acciones en los que las concepciones, las actitudes, las intenciones, los motivos, etc., de los actores intervienen activamente en el decurso de esos procesos.

Ello significa que tras la aparente inexorabilidad de algunos procesos puede haber, en realidad, una pluralidad de opciones. Hacernos conscientes de las mismas es poder optar racionalmente por un modelo de cambio. Si el impacto de la adopción generalizada de las nuevas tecnologías es de la profundidad y el alcance previstos, es claro que su introducción no debería dejarse a la sola espontaneidad social, sino que debería atenerse a un modelo de cambio social planificado que respondiese a los intereses generales de la sociedad. Por supuesto que ese cambio planificado puede y debe llevarse - a efecto democráticamente, es decir, con la participación activa de aquellos a quienes vaya a afectar más directamente. De este modo, los motivos para la adopción de determinadas innovaciones se hacen más transparentes y los posibles conflictos de intereses también.

En momentos de un cierto auge neoliberal, el concepto de «cambio social planificado» puede parecer démodé. Pero no veo otra forma de evitar las consecuencias no queridas del cambio, o de inducir una mentalidad de apertura y flexibilidad hacia las innovaciones, más que a través de un esfuerzo de autoconsciencia y control colectivos de los procesos sociales.

La subjetivización del cambio la entiendo, pues, como una participación colectiva consciente en el establecimiento de sus fines y en la fijación de medios para su consecución. Tanto para un programa de introducción y diseminación generalizada de una innovación tecnológica, como para comprobar los efectos de su adopción, es necesario tener en cuenta las actitudes y la mentalidad del sector social de que se trate, los intereses en juego, sus expectativas y valores, sus posibles resistencias. El conocimiento concreto de esas dimensiones proporcionaría un marco de interpretación más preciso sobre la aceptación o rechazo de determinadas tecnologías, sobre las razones subyacentes de su adopción, muchas veces no por un nexo estrictamente racional de medios-fines, así como las consecuencias que pueda 
tener su introducción y generalización en el cambio de pautas tradicionales y de relación social, y en la (subjectividad) individual.

Harían falta estudios empíricos (concretos) sobre los efectos de las tecnologías específicas, teniendo en cuenta las fases por las que pasa una innovación hasta su uso generalizado. Estudios longitudinales que, a su vez, deberían ser tenidos en cuenta y servir de base para sucesivas introducciones de cambio y su planificación. No existen muchos estudios empíricos de esta índole que permitan extraer conclusiones claras sobre los efectos psicosociales de estas nuevas tecnologías, a algunos de los cuales me referiré en seguida. Sí existen en cambio muchas conjeturas, profecías, etc, sobre los pros y los contras que puedan derivarse de un uso generalizado de la electrónica.

Una reflexión reciente, en este sentido, la constituye el libro de Julián Marías Cara y cruz de la electrónica (1985). En él se señalan como potencialidades de la electrónica: $\mathrm{El}$ incremento de la información disponible, capacidad de memoria, facilitación de las comunicaciones personales, dilatación del mundo accesible, incremento de las acciones posibles, ahorro de esfuerzo, e instantaneidad. Resulta difícil no estar de acuerdo con estas categorías que, debidamente expandidas, pueden describir bastante bien el horizonte de posibilidades que abre la electrónica. En cuanto a sus posibles consecuencias negativas en el pensar humano señala Marías, entre otras: automatización del saber, mera facticidad, atomización, tendencia a la cuantificación, propensión a simplificar las cuestiones, reducción de la realidad humana a los modelos de las ciencias naturales, limitación de la esfera del saber al alcance de un computador, lo que en epistemología han llegado a llamar la ley del instrumento, (es decir, si tenemos un instrumento para formular nuestros pensamientos, nuestras investigaciones, es muy posible que nos dejemos llevar más por la estructura de ese instrumento que por preguntas genuinas propias) y en última instancia renuncia a la razón. Desde esta perspectiva el ordenador puede legitimar una versión rutinizada de un estilo de pensamiento empobrecido del que podría quedar ausente la razón y su ejercicio.

En un plano más genérico, las técnicas electrónicas, precisamente por las características positivas que hemos señalado al principio, permiten una identificación masificada de cada persona, con la posibilidad de incluir en la misma todo tipo de informaciones y de registrar sucesivamente sus trayectorias. Obviamente esto puede ser útil en áreas como la sanidad o en la racionalización del cumplimiento de las obligaciones fiscales o en la seguridad pública, pero también pueden sustituir con infinita ventaja a los viejos ficheros de las policías políticas. Si a ello añadimos las posibilidades prácticamente ilimitadas de invadir la privaticidad, la perfección con que se cierra 
el círculo del control social, es sin duda inquietante. Las nuevas tecnologías. pueden ser un serio riesgo para la libertad.

Ahora bien, ¿en qué medida las predicciones en torno a los posibles efectos de las nuevas tecnologías se han ido cumpliendo en el plano real? Aquí tendremos que echar mano de una evidencia comparada aunque tentativa. En un número monográfico reciente del «Journal of Social Issues», dedicado precisamente al estudio de los efectos psicosociales de los ordenadores, se llega a la conclusión de que la experiencia, tanto la de los estudios empíricos existentes como la de los implicados en el uso de ordenadores, tiende a desconfirmar las profecías y grandes visiones sobre los mismos, y a poner de relieve otros problemas relacionados con el contexto social en el que son usados (Caporael, 1984). Esta afirmación tiene en consideración estudios sobre tres áreas: la privaticidad, la educación y el empleo. Es decir, no se han cumplido cambios revolucionarios que se esperaban iban a producirse en las dos últimas décadas.

La conclusión más genérica de este número monográfico es que la tecnología de los ordenadores, al menos en su estadio de transición, amplifica la realidad de las circunstancias actuales y los problemas de vivir en una sociedad compleja (Caporael y Thorngate, 1984). Así, por ejemplo, entre las mujeres que trabajan en casa con el ordenador, el conflicto de roles experimentado debido a la no separación física entre el trabajo profesional y el doméstico es mayor que entre los hombres. O el dilema de status en el que se encuentran los profesores ante el hecho de tener que aprender, en ocasiones, de alumnos expertos en el manejo del ordenador, o al menos más expertos que ellos. Los que somos profesores nos hemos visto algunas veces en esta tesitura. Esta conclusión tiene también plenamente sentido si la formulamos para un nivel más macrosociológico: la conflictividad social tenderá a aumentar a corto y medio plazo con la introducción de nuevas tecnologías en los contextos de trabajo.

En cualquier caso, es poco lo que sabemos empíricamente sobre los efectos psicosociales de las nuevas tecnologías. Sabemos ya que por el mero hecho de su difusión y por el tiempo empleado en ellas, están ya afectando directamente la conducta y la experiencia de amplios sectores. sociales. Pero cómo lo están haciendo, en qué grado, en qué aspectos específicos de la experiencia personal, no lo sabemos. No conocemos tampoco cuál es la imagen que de las distintas tecnologías tiene la sociedad. El ritmo de cambio es en sí mismo un factor de confusión adicional. En este sentido, dos psicólogos evolutivos, expertos en estos temas, refiriéndose a la introducción en el aula de nuevas tecnologías, acaban de señalar, cito textualmente: «Naturalmente todo esto tiene que tener una influencia sobre el desarrollo de los niños, aunque no sabemos aún qué tipo de influencia, lo 
profunda que será y hasta qué punto alterará este desarrollo» (Del Val y Enesco, 1985, p. 14). Lo que esto quiere decir es que hay que seguir investigando.

Mientras tanto, conviene insistir en que tanto las potencialidades como los peligros no son intrínsecos a la tecnología, sino que están en los valores contradictorios de quienes la generan, la difunden y la utilizan. No se debe atribuir a la técnica unas responsabilidades que sólo cabe inscribir en el marco social del que son resultado. La autonomización y la objetivación del proceso científico-técnico son una forma de desresponsabilización colectiva, además de una insuficiencia analítica. No basta, por tanto, con analizar la pragmática estructura de los propios medios técnicos y de sus usos ya reales o incipientes. Hay que desentrañar la estructura de fines, de valores, de intenciones, de expectativas, etc., que subyacen y orientan la concepción, el desarrollo, la puesta a punto y la diseminación de la misma. Porque si no hay una legalidad inmanente y necesaria en el desarrollo tecnológico, es entonces el resultado de un proyecto cuyo sentido hay que desvelar. Y detrás de los proyectos siempre hay alguien, un sujeto individual o colectivo. Un sujeto con unos intereses, con una ideología, unos fines, una estrategia.

De ahí que el único modo de superar esa ambigüedad inherente a los posibles efectos de la técnica sea reconducir el proyecto que la genera, como parte integrante del mismo, a una discusión colectiva de los fines, soldar intelectual y prácticamente el discurso de la racionalidad instrumental con el de la racionalidad sustantiva, intentar recomponer esa escisión que el mundo moderno ha consumado, mediante el claro predominio de la racionalidad instrumental subordinada a la lógica del poder y de la dominación. Como ha señalado Habermas, cito textualmente: «Lo que hay que hacer más bien es poner en marcha una discusión políticamente eficaz que logre poner en relación, de forma racionalmente vinculante, el potencial social de saber y poder técnicos con nuestro saber y querer prácticos (...). Sólo cuando seamos capaces de sostener esta dialéctica con conciencia política, podremos también tomar las riendas de la mediación de progreso técnico con la práctica de la vida social (...)» (Habermas, 1984, p. 129). 
Dimensiones subjetivas del cambio

\section{REFERENCIAS}

Marías, Julián: Cara y cruz de la electrónica. Espasa-Calpe, Madrid, 1985.

Caporael, L. R. y Thorngate, W.: Introduction: towards the Social Psychology of computing. «Journal of Social Issues». Vol. 40, núm. 3, 1984, pp. 1-13. Caporael, L. R.: Computers, prophecy, and experience: a bistorical perspective. «Journal of Social Issues». Vol. 40, núm. 3, 1984, pp. 15-29.

De Val, J. y Enesco, I.: Prólogo al libro de Greenfield, P. M.: El niño y los medios de comunicación. Ed. Morata, Madrid 1985, pp. 11-16.

Habermas, J.: Ciencia y técnica como «ideología». Ed. Tecnos, Madrid 1984. 